\title{
Transparência nas relações público-privadas para prestação de serviços de saúde no estado de São Paulo
}

Transparency in public-private relations for the provision of health services in the state of São Paulo

Transparencia en las relaciones público-privadas para la prestación de servicios de salud en el estado de São Paulo

\author{
Pedro Ivo Biancardi Barboza1 \\ Maria da Penha Vasconcellos ${ }^{2}$ \\ Fernando Mussa Abujamra Aith ${ }^{3}$
}

\begin{abstract}
Resumo
Objetivos: verificar se os instrumentos e mecanismos de inclusão e transparência disponíveis ao cidadão no estado de São Paulo permitem o exercício da democracia sanitária e o controle social das metas e resultados da contratualização da prestação de serviços de saúde. Metodologia: pesquisa documental, realizada em sistemas oficiais de informação, sobre a contratualização de entidades públicas e/ou privadas para prestação de serviços públicos de saúde pelo estado de São Paulo/ e pesquisa documental em Portais da Transparência e financeiros, de âmbito estadual, para aferição de metas e resultados dessas contratações. Resultados: as iniciativas privadas complementares ao papel do Estado atuam sob nítida dependência financeira da esfera governamental. Há um déficit significativo de informações para a construção ou padronização dos dados de performance, inviabilizando a fiscalização das políticas públicas em saúde e a aferição do custo/efetividade dos serviços de saúde prestados diretamente pela Administração Pública e pelo setor privado. Conclusão: os dados encontrados na pesquisa não aferiram uma maior eficiência dessas novas formas de coalizões e alianças com a sociedade civil, em que pese o fato do Poder Público não ter capacidade de absorver diretamente toda a assistência hoje prestada por intermédio dos entes privados e do terceiro setor. A falta de instrumentos de accountability governamental ocasiona falta de transparência no controle de metas e resultados das contratualizações.
\end{abstract}

\section{Palavras-chave}

Colaboração Público-Privada. Administração Pública. Contratos. Controle Social. Saúde.

\begin{abstract}
Objectives: to verify whether the instruments and mechanisms for inclusion and transparency available to citizens in the state of São Paulo allow for the exercise of sanitary democracy and social control of the goals and results of the contractualization of the provision of health services. Methods: documentary research, conducted in official information systems, on the contracting of public and/or private entities for the provision of public health

\footnotetext{
1 Doutorando em Saúde Global e Sustentabilidade, Universidade de São Paulo, São Paulo, SP, Brasill. https://orcid.org/0000-0002-6932-368X. E-mail: peivo_barboza@usp.com

2 Doutorado em Saúde Global e Sustentabilidade, Faculdade de Saúde Pública, Universidade de São Paulo, São Paulo, SP, Brasil; Professora Associada III, Programa de Pós-graduação em Saúde Pública, Universidade de São Paulo, São Paulo, SP, Brasil. https://orcid.org/0000-0003-2666-9485. E-mail: mpvascon@usp.com

${ }^{3}$ Pós-doutorado, Faculdade de Direito, Université Paris II, Paris, França; Professor Titular, Departamento de Política, Gestão e Saúde, Faculdade de Saúde Pública, Universidade de São Paulo, São Paulo, SP, Brasil; professor visitante, da Université Paris V, Descartes, França. https://orcid.org/0000-0003-1971-9130. E-mail: fernando.aith@usp.com
} 
services by the state of São Paulo/ and documentary research on Transparency and financial Portals, at the state level, for measurement of goals and results of these contracts. Results: private initiatives that complement the role of the State act under a clear financial dependence on the government sphere. There is a significant deficit of information for the construction or standardization of performance data, making it impossible to monitor public health policies and to measure the cost/effectiveness of health services provided directly by the Public Administration and by private sector. Conclusion: the data found in the research did not show a greater efficiency of these new forms of coalitions and alliances with civil society, even though the Government is not able to directly absorb all the assistance currently provided through private entities and the third sector. The lack of governmental accountability instruments causes a lack of transparency in the control of contractual targets and results.

\section{Keywords}

Public-Private Sector Partnerships. Public Administration. Contracts. Social Control. Health.

\section{Resumen}

Objetivos: verificar si los instrumentos y mecanismos de inclusión y transparencia a disposición de los ciudadanos en el estado de São Paulo permiten el ejercicio de la democracia sanitaria y el control social de las metas y resultados de la contratación de la prestación de servicios de salud. Metodología: investigación documental realizada en sistemas de información oficiales sobre contratos con entidades públicas y/o privadas para la prestación de servicios de salud pública en el estado de São Paulo e investigación documental en Portales de Transparencia y financieros, a nivel estatal, para medir metas y resultados de estas contrataciones. Resultados: las iniciativas privadas que complementan el rol del Estado actúan bajo una clara dependencia financiera del ámbito gubernamental. Existe un importante déficit de información capaz de conducir a la construcción o estandarización de datos de desempeño, imposibilitando el seguimiento de las políticas de salud pública y la medición del costo/efectividad entre los servicios de salud brindados directamente por la Administración Pública y los brindados por el sector privado. Conclusión: No existe evidencia científica o empírica que asegure una mayor eficiencia en estas nuevas formas de coaliciones y alianzas con la sociedad civil, a pesar de que el Gobierno no puede absorber directamente toda la asistencia que actualmente se brinda a través de las entidades privadas y del tercer sector. Además, la falta de instrumentos gubernamentales de rendición de cuentas termina provocando poca transparencia en el control de metas y resultados colimados en los contratos establecidos.

\section{Palabras clave}

Asociación entre el Sector Público-Privado. Contratos. Administración Pública. Control Social Formal. Salud.

\section{Introdução}

A redefinição do papel do Estado a partir da Emenda Constitucional no 19/98 (1) fez com que organismos privados ganhassem espaço na produção de bens e serviços que eram prioridade do setor público. A descentralização de serviços públicos fomentada pela Emenda trouxe como vantagens a pluralização de oferta de serviços sociais, maior desburocratização da gestão social e a responsabilidade de dirigentes e participantes pela organização, cujo controle é feito pelo Poder Público, pelo Ministério Público, pelo Judiciário e pela sociedade. 
O Poder Público continua a garantir os direitos sociais, mas transfere sua provisão ou oferta para organizações quase estatais, mediante categorias de gestão privada, descentralização administrativa, cumprimento de exigências contidas no instrumento contratual e orientação para resultados, com controle a posteriori. Houve a divisão das atividades estatais em dois tipos: as atividades exclusivas do Estado correspondem à legislação, à regulação, à fiscalização, ao fomento e à formulação de políticas públicas e pertencem ao domínio do núcleo estratégico do Estado, sendo portanto, realizadas pelas secretarias, pelas agências executivas e pelas agências reguladoras; as atividades não exclusivas do Estado correspondem aos serviços de caráter competitivo e concorrencial e às atividades auxiliares ou de apoio (2), culminando com um movimento de privatização e ampliação da cooperação entre entidades no que hoje se chama Administração Cooperativa.

A partir dessa nova conjuntura, proliferaram, institutos consensuais como os convênios, os acordos de programas e contratos de gestão nos quadros da Administração Pública contemporânea, frutos dessa superposição entre o Estado e o privado na criação e execução de políticas públicas. A Administração Pública abre mão de seus poderes, caracterizados pela unilateralidade e imperatividade, para realizar acordos com os particulares destinatários da aplicação concreta de tais poderes, proporcionando uma colaboração mais ativa dos administrados (3). Como decorrência dessas novas exigências cidadãs, ganha maior relevo princípios como os da eficiência, da participação e da transparência, e inicia-se um processo de fragmentação administrativa no qual o setor privado assume um papel de agente colaborador e cooperador no desenvolvimento e na busca pela implantação de um modelo de Estado de bem-estar. Tal fragmentação das atividades da Administração Pública se dá sob uma ótica contratual de bilateralidade, com novas formas e instrumentos de atuação nos quais se observam, muitas vezes, interesses multilaterais envolvidos (4). O direito público restaura a presença do empresário na economia e passa a valorizar a participação popular na gestão e no controle da atividade administrativa.

Observa-se também a desconstrução do direito administrativo como conhecemos, com o abandono de sua vertente autoritária para valorizar a participação de seus destinatários finais quanto à formação da conduta administrativa (5). Torna-se mais participativo, mais focado em negócios, na priorização de resultados e na fixação metas para obtê-los, consagrando uma adequada estruturação jurídica para a cooperação com entes privados. 
A função administrativa - que consistia no poder/dever de adotar, na margem de discricionariedade aberta pela lei, a decisão mais eficiente para a consecução do bem comum (6) - passa a ter como preocupação preponderante não mais limitar e enquadrar comportamentos, mas sim, alcançar certos efeitos econômicos e sociais por meio da diminuição da distância antes existente entre a Administração Pública e o administrado. Passam a ser adotados instrumentos consensuais que permitem à Administração Pública o cumprimento das tarefas que essa nova concepção impõe e dão maior legitimação às decisões adotadas, o que vai ao encontro da qualificação federal de Estado Democrático Social trazida pela Constituição Federal.

O novo administrar já não significa aplicar a lei de ofício, isto é, a função administrativa não mais se limita à mera realização concreta da prescrição normativa, mas sim condicionála à satisfação concreta de finalidades públicas. Isso permite que certas entidades se tornem interlocutores no diálogo, inclusive para a criação do direito aplicável, mediante uma relação jurídica paritária que se estabelece entre a Administração Pública e o cidadão, ou entre o Estado e as entidades públicas, tendo o cidadão como destinatário permanente da ação estatal (7). Outro efeito é a transformação nas fontes do direito para resultados, já que o princípio da legalidade formal perde sua centralidade, fazendo com que as normas jurídicas passem a ter um conteúdo mais programático, aberto, de forma a propiciar a participação competitivo-colaborativo dos agentes econômicos, ampliando a importância do campo regulatório (8).

Caminhamos, então, na direção de modelos de colaboração e cooperação entre público e privado, também observados no campo da saúde pública, acolhendo a participação democrática da sociedade, estimulando a dinâmica da iniciativa privada e iniciando um período de retração de ingerência direta do Estado (9). Ganha maior ênfase, assim, a desconcentração, a descentralização e a terceirização de funções do Estado para tais entes e entidades. O Estado não tem sido capaz de garantir a prestação em sua totalidade, o que incentiva a conformação público/privada, não obstante tal conformação contribua para estruturar um modelo de proteção social mais liberal, em contrapartida ao modelo de saúde pública previsto pela Constituição Federal.

Essa mudança de paradigma também se operou na saúde, elevada a direito pela Constituição Federal e tendo, como forma de garantia de seu exercício, prestações estatais estruturadas na própria Carta Maior. Houve ampliação da autonomia dos entes da Administração Indireta; da participação dos entes do terceiro setor, por meio da chamada 
publicização; e dos entes privados, por meio da aplicação do princípio da subsidiariedade como técnica de repartição de interesses ou de domínios materiais de decisão relativos ao poder público. Isso permite o abandono de um modelo rígido de repartição de competências públicas para dar ensejo a um modelo mais flexível, ancorado na descentralização e desconcentração de serviços (4) para várias entidades, ocasionando uma fragmentação não só administrativa, mas também regulatória.

A fragmentação administrativa pode ser observada na atual gestão dos hospitais estaduais da administração direta por meio das parcerias com Organizações Sociais via contratos de gestão, iniciadas em 1998, cujo foco foi conseguir maior eficiência e incentivar mudanças para obtenção de melhores resultados (10). Tais readequações e reorganizações suscitaram uma ênfase cada vez mais crescente à chamada accountability governamental, com a abertura de dados que possibilitem o controle das ações de Estado e políticas públicas. É a corporificação do chamado controle social e a possibilidade do exercício da democracia sanitária, em especial pós-edição da Lei n 12.587, de 18 de novembro de 2011 (11), cuja finalidade foi dar maior transparência ao aprimoramento do desempenho do setor público e ao exercício da cidadania nas ações de Estado. De fato, a transparência é um corolário da democracia sanitária, regime de governo do povo que, aplicado aos temas relacionados à saúde individual e coletiva, permite aos cidadãos participarem e influenciarem ativamente, de forma deliberativa e consultiva, nos processos de tomada de decisões estatais de saúde de competência dos Poderes Legislativo, Executivo e Judiciário (12). Garante o direito à informação ao cidadão sobre a implementação, acompanhamento e resultados dos programas, projetos e ações não só dos órgãos e entidades públicas, mas destas com o campo privado, bem como das metas e indicadores propostos. A Organização Pan Americana de Saúde (OPAS) destaca que sistemas de saúde eficientes e participativos requerem um compromisso da sociedade com mecanismos claros de inclusão, transparência, prestação de contas, participação multissetorial, diálogo e consenso entre os diferentes atores sociais, como também um compromisso político firme e de longo prazo na formulação de políticas, legislações, regulamentações e estratégias voltadas ao acesso a serviços integrais, oportunos e de qualidade (13).

Assim, o presente artigo tem como objetivo verificar se os instrumentos e mecanismos de inclusão e transparência disponíveis ao cidadão no estado de São Paulo permitem o exercício da democracia sanitária e o controle social das metas e resultados da contratualização da prestação de serviços de saúde. 


\section{O reconhecimento da saúde como direito na ordem constitucional brasileira}

A partir de 1988, o reconhecimento da saúde como um direito na Constituição Federal e a constitucionalização de um sistema universal de saúde, resultado da transição para a democracia, fez emergir o capítulo social da Constituição Federal e culminou com a inclusão dos chamados outsiders, ou seja, daqueles que não acumulavam canais de acesso por não estarem inseridos no mercado formal de trabalho, dado que, até então, o vínculo trabalhista era um requisito de acesso a aposentadoria e serviços de saúde (14).

O Estado de bem-estar social brasileiro (welfare state) assume então obrigações perante os cidadãos, por meio da oferta de um conjunto de serviços e benefícios sociais de alcance universal por ele promovidos, com a finalidade de garantir certa harmonia entre o avanço das forças de mercado e uma relativa estabilidade social, e de dialogar com os anseios dos mais diferentes conjuntos de atores sociais.

A saúde, tal qual prevista na Constituição Federal, incorporou o direito dos cidadãos a um sistema público e universal de saúde (15), com acesso garantido às ações e serviços de saúde para toda a população, em todos os níveis de assistência, sem a possibilidade de imposição de qualquer preconceito ou privilégio, em atendimento aos princípios da igualdade e da equidade.

A Carta Maior corporificou uma estrutura complexa de atenção à saúde pública e privada, reguladas geralmente a partir de uma política de Estado, definida na Constituição Federal por meio de normas programáticas que consagram a postura do Estado como agente do desenvolvimento e da justiça social, compostas por várias políticas de ação governamental que implicam na elaboração de metas, definição de prioridades e meios de execução para a consecução dos compromissos constitucionais estabelecidos, dentro da estrutura institucional cooperativa denominada federalismo sanitário brasileiro (16)

Porém, na medida em que a dimensão dos serviços sociais do Estado aumentava, sua efetividade não se demonstrava suficiente, razão pela foi incorporada no Brasil a tendência internacional de desmonte dos sistemas de proteção social, traduzido, mas especificamente na redução do gasto público. Mesmo como um dos maiores sistemas universais do mundo, o SUS sofre desde seu nascedouro com a concorrência do setor privado, além de incapacidade do Estado em garantir o direito universal à saúde, em especial por conta de políticas de ajuste fiscal que culminaram como a Desvinculação da Receita da União (DRU), que desde 1994 diminui o orçamento federal em 20\% - percentual 
recentemente aumentado para $30 \%$ até 2023 , e a desvinculação dos orçamentos estaduais e municipais (15).

Consagra-se um Estado subsidiário, que não considera sua prestação como prerrogativa exclusiva, já o arcabouço jurídico do sistema público universal e público de saúde apresenta um caráter dual da prestação, ou seja, a própria Constituição Federal permite as instituições privadas podem participar do SUS de forma complementar. A Constituição Federal faz uma distinção entre uma esfera pública de prestação de serviços de saúde (o SUS), prevista em seu artigo 198, e uma esfera livre à iniciativa privada para prestação de tais serviços, ex vi dos artigos $197,198, \S 1^{\circ}$, e $199, \S 1^{\circ}$. Ou seja, a participação de instituições privadas no SUS é também reproduzida sistemática infraconstitucional, dado que o artigo $4^{\circ}$, $\S 2^{\circ}$, da Lei n. 8.090/90(19) estabelece que "a iniciativa privada poderá participar do Sistema Único de Saúde (SUS), em caráter complementar", e o art. $8^{\circ}$ do mesmo diploma legal prevê que "[...] as ações e serviços de saúde, executados pelo Sistema Único de Saúde (SUS), seja diretamente ou mediante participação complementar da iniciativa privada...".

Por seu turno, o artigo 20 da mesma Lei n. 8080/90 estabelece que "os serviços privados de assistência à saúde caracterizam-se pela atuação, por iniciativa própria, de profissionais liberais, legalmente habilitados, e de pessoas jurídicas de direito privado na promoção, proteção e recuperação da saúde". Assim, a Lei Orgânica da Saúde ratifica que a iniciativa privada venha também a atuar na esfera pública. Como a própria Constituição Federal traz, em relação ao SUS, essa possibilidade de participação complementar dos entes privados, ganhou relevo à gestão compartilhada da saúde pública, por meio de acordos e contratos, que favoreceu as mudanças institucionais na Administração Pública para que agisse em consenso, permitindo a gestão direta pela comunidade dos serviços de saúde fora do aparato burocrático do Estado, em que pese seu apoio direto e sua assistência permanente (17).

Desse modo, no âmbito dos serviços prestados em regime público, podemos falar em duas formas de prestação: os serviços prestados diretamente pelo Poder Público, que constituem o cerne dos serviços oferecidos pelo SUS e cuja execução há de estar a cargo da Administração Pública e os serviços prestados complementarmente pelos entes privados, com ou sem finalidade lucrativa. Como visto, tais serviços podem ser prestados de forma direta ou indireta, na medida em que se refiram ou não aos serviços complementares trazidos pelo artigo $199, \S^{\circ}$, da Constituição Federal. 


\section{A substituição do papel da Administração Pública na prestação de serviços públicos}

A diminuição do papel dos governos fez com que o modelo de Administração Pública Estatista existente desse espaço a um modelo de Administração Pública Negocial, focada em resultados (18). Para a nova Administração Pública, os acordos são desejáveis, surgindo novas formas de pactuação - sejam entre órgãos da Administração Pública, sejam com a iniciativa privada - como forma de se revigorar a capacidade de gestão e implementação de políticas públicas do Estado, que se retira da execução efetiva de algumas atividades mediante o trespasse de sua exploração a particulares, por meio programas de privatização, terceirização, parcerias, contratos de gestão, abertura a competições ou outorga de concessões e permissões. O Estado devolve à sociedade uma posição ativa e construtiva e a legitimidade da iniciativa privada, notadamente pelo desenvolvimento de entidades intermédias, que multiplicam e descentralizam os polos de poder, prenunciando o surgimento e o crescimento de uma policracia (8). Instâncias de governo e particulares, com ou sem fins lucrativos, tornaram-se sócias na promoção do desenvolvimento econômico e social, apresentando uma organização mais flexível, ágil e com atuação descentralizada, na busca de maior eficiência em seus serviços.

Aproveitando-se do caráter dual do sistema de saúde brasileiro, a política de saúde incorpora formalmente a assistência privada não só de maneira complementar, dado que não mais se considera a prestação de serviços de saúde como prerrogativa exclusiva estatal. Isto fica claro no próprio arcabouço jurídico do sistema público e universal de saúde, dada a distinção existente entre uma esfera pública de prestação de serviços de saúde (o SUS), prevista no artigo 198 da Constituição Federal, e uma esfera livre à iniciativa privada para a prestação de tais serviços, pelos artigos 197, 198, $\$ 1^{\circ}$, e $199, \S 1^{\circ}$, todos da Constituição Federal.

Com a Emenda Constitucional $n^{\circ} 19 / 98$, permite-se transferir à sociedade e a outras esferas de governo atividades que poderiam ser melhor executadas no setor público não estatal, privado, proporcionando novas formas de atuação pactuadas no âmbito da Administração Pública, dentro do federalismo cooperativo (19).

A primeira delas é a interadministrativa, a qual, além de complementar a prestação direta dos serviços de saúde pelo Estado, se utiliza das pessoas jurídicas estatais que compõem o aparato jurídico-público da Administração Indireta (8), como as autarquias; fundações; empresas públicas; sociedades de economia mista; consórcios públicos; e também os serviços sociais autônomos, mediante a ampliação de suas autonomias 
administrativo-constitucionais e cuja atuação é especialmente materializada por meio de contratos de gestão, convênios ou termos de fomento.

A segunda forma de atuação pactuada consiste em ajustes entre entidades estatais e entes privados sem fins lucrativos, que compõem o terceiro setor, em cujo âmbito encontram-se as organizações sociais, as organizações sociais civis de interesse público e as organizações da sociedade civil, alheios, portanto, à estrutura governamental (8).

A terceira forma de atuação pactuada com o chamado Setor Espelho, que são entes sob regime privado, nascidos como extensões informais de órgãos públicos, autarquias, fundações governamentais, e mesmo empresas estatais em geral, sob a justificativa de apoiá-las; são os casos das fundações privadas de apoio. (8)

Já a quarta forma corresponde à atuação pactuada com o Setor Autônomo, que corresponde ao conjunto de entidades criadas por lei federal com a designação de Serviço Social Autônomo e que recebem recursos de contribuições legais, dedicam-se a serviços de natureza social ou ao fomento (20).

A quinta e última forma de atuação pactuada são as parcerias público-privadas, assim definidas como "uma forma de cooperação estruturada entre parceiros públicos e privados para o planejamento ou construção e/ou a exploração de instalações nas quais compartem ou realocam riscos, custos, benefícios, recursos e responsabilidades" (21); e por meio das entidades filantrópicas ou beneficentes mediante chamada pública ou convênios.

Tais pactuações com a sociedade civil e entidades da Administração Indireta têm como objetivo propiciar uma melhor orientação para o cidadão, a partir de três pilares: i) controle de resultados dos contratos de gestão, instrumento escolhido para celebração de tais parcerias, pela sociedade (controle social), Ministério Público, Poder Judiciário e Tribunais de Contas (controle externo); e pelas Controladorias e Corregedorias (controle interno da Administração) -; ii) transferência de serviços sociais, incluindo aí a saúde, para o setor público não estatal; e iii) terceirização de atividades auxiliares ou de apoio.

\section{A transparência como corolário da democracia sanitária e de proximidade com o serviço público de saúde}

Esses novos paradigmas incentivaram a participação do cidadão no entendimento das necessidades de saúde na sociedade em que vive e sua colaboração ativa na busca de soluções eficazes para uma melhor proteção da saúde individual e coletiva, que constituem elementos essenciais e fundantes da noção de saúde como um direito (22). 
De fato, a efetivação do direito universal, igualitário e integral à saúde, tal como preconizado por nossa Constituição, depende largamente da democracia sanitária, que consiste na participação dos cidadãos na definição dos contornos do direito à saúde - como formulação de políticas; legislações; regulamentações e estratégias voltadas ao acesso à saúde. A democracia sanitária pressupõe que o Estado, para dar conta de seu dever constitucional de proteção do direito à saúde, crie, incentive e desenvolva um ambiente de ampla participação democrática da sociedade na tomada de decisões estatais em saúde (13), pois consagra um papel participativo à sociedade no nível das instituições. O artigo 198, inciso III, da Constituição Federal, sancionou a participação popular e a descentralização da tomada de decisões e estabeleceu mecanismos para a participação dos cidadãos na formulação, administração e monitoramento de políticas sociais como diretriz do SUS. Todas as pessoas são portadoras do direito à saúde e, em decorrência, todos devem participar dos processos de elaboração e implementação das políticas relacionadas aos serviços de saúde e ao ambiente físico e social que os cercam (23) - mediante a utilização de mecanismos que sejam justos e respeitáveis - e que tenham influência nas condições sociais e resultados em saúde, possibilitando o aprofundamento das questões locais, nacionais e até mesmo globais relativas à saúde.

Portanto, na onda de redefinições da prestação de serviços de saúde, há que se registrar a necessidade premente de investimento também no desenvolvimento de novas ferramentas de gestão e inovação que permitam o controle social pelo cidadão, com a finalidade de melhorar a eficácia do setor público mediante a criação de uma cultura de governança que tenha como pilares a participação; o Estado de Direito; a transparência; a responsabilidade; a orientação por consenso; a igualdade; a inclusividade; a efetividade e eficiência; e, por fim, a prestação de contas (accountability) (8), ou seja, efetivo controle e fiscalização do cumprimento das metas dos programas de saúde estabelecidos. Lembremos que o está em jogo é o próprio conteúdo do direito à saúde e as formas para sua efetivação, já que a questão relativa à transparência, enquanto desdobramento da democracia sanitária, envolve a compreensão sobre como esse direito é definido e executado pelas decisões estatais; sobre as formas de ampliação dos modelos de participação democrática em saúde; e sobre a própria relação jurídico-administrativa entre Administração e administrado.

Todavia, ainda há um déficit significativo de transparência e informação nos mecanismos virtuais de consulta disponíveis. Há a necessidade de construção de uma metodologia comum pelos órgãos públicos para a apresentação das informações, de modo 
a encorajar o exercício da democracia sanitária. Há também sérias dificuldades relativas à abertura dos dados sobre os resultados dos modelos de prestação de serviços adotados na área da saúde, o que compromete sua fidedignidade.

Mesmo assim, a transparência - mediada pelas tecnologias da informação e comunicação e instrumento de controle social que permite a aferição de resultados, a verificação da qualidade do serviço público e a influência do cidadão-usuário nas políticas de saúde - deve ser vista como um corolário da própria democracia sanitária.

\section{Metodologia}

Para uma compreensão adequada da atual regulação jurídico-normativa entre o público e o privado nos serviços de saúde, utilizamos o estado de São Paulo como objeto de pesquisa, visto que as parceirizações apresentam-se como um modelo consolidado desde 1998, servindo de exemplo para outros municípios e estados do Brasil, com adaptações regionais e locais e resultados variados. Em São Paulo, teve como objetivo uma maior agilidade e autonomia administrativa para a gestão de novos hospitais, condições difíceis de serem encontradas, de modo geral, nas instituições sob Administração Direta naquele estado, em especial na área de recursos humanos (10). No presente trabalho, foi considerado apenas os dados relativos ao serviço público assistencial, não incluindo os serviços de vigilância em saúde, no período de janeiro a dezembro nos anos de 2015 a 2019.

Primeiramente, realizou-se uma pesquisa documental por intermédio de consulta aos registros contratuais oficiais existentes sobre a prestação de serviços de saúde nos seguintes portais: i) Portal Financeiro do Gestor (CGOF/SES)4; ii) Portal da Transparência da Secretaria Estadual da Saúde de São Paulo (SES) ${ }^{5}$; iii) Sistema de Informações Hospitalares do SUS (SIH/SUS) do Departamento de Informática do SUS - DATASUS, do Ministério da Saúde ${ }^{6}$; e, iv) o Sistema de Informações Ambulatoriais do SUS (SAI/SUS), do Departamento de Informática do SUS - DATASUS, do Ministério da Saúde?.

Como segundo passo, delineou-se uma construção classificatória, com os seguintes critérios: a) instrumento de formalização, b) objeto da contratação, c) escolha do parceiro, d) fomento, e) compras, f) contratação de pessoal; g) forma de controle; h) órgão de controle; e, i) exemplo de pessoas jurídicas de cada tipo mencionado.

\footnotetext{
${ }^{4}$ http://www.fazenda.sp.gov.br/CPATES/Sistema/PesqlntrJuri.aspx

5 http://www.portaldatransparencia.saude.sp.gov.br/unidades.php

6 http://tabnet.datasus.gov.br/cgi/deftohtm.exe?sih/cnv/qisp.def

7 http://tabnet.datasus.gov.br/cgi/deftohtm.exe?sih/cnv/qisp.def
} 
Na segunda etapa do processo, dividiu-se a análise em dois passos: no primeiro passo, foi realizado o levantamento dos seguintes documentos por meio do Serviço de Informação ao Cidadão (SIC): i) relatório final produzido no âmbito da Comissão Parlamentar de Inquérito das Organizações Sociais de Saúde (CPI das OSs) (25), que ocorreu na Assembleia Legislativa do Estado de São Paulo (Alesp) a fim de investigar supostas irregularidades em serviços prestados em hospitais e unidades de saúde estaduais. O processo foi instruído com relatório do Tribunal de Contas do Estado de São Paulo (TCE/SP), que apontou as principais irregularidades encontradas nas fiscalizações dos contratos de gestão celebrados com as organizações sociais (OSs); e, ii) informações da SES relativas a estudos avaliativos ou que proporcionassem a obtenção de evidências científicas para comprovar vantagens entre os modelos de gestão de saúde pela Administração Direta, Indireta ou privada, sua economicidade ou superioridade competitiva.

No segundo passo, foram realizadas consultas a informações e documentos junto ao Portal Financeiro do Gestor (CGOF/SES); ao Portal da Transparência da Secretaria da SES; e ao CPATES, da SEFP, a fim de verificar: i) se os dados e informações disponíveis eram aptos a possibilitar a construção de um estudo analítico sobre o custo e a efetividade entre os serviços de saúde prestados diretamente pela Administração Pública e aqueles prestados por meio das contratualizações; ii) se tais dados e informações disponibilizados nos Portais da Transparência traziam avaliações periódicas sobre o cumprimento das metas, sobre os resultados contratados, e sobre os padrões de performance dos serviços de saúde nas relações de cooperação com entes da Administração Indireta e entidades privadas e do terceiro setor, permitindo o controle social. Em seguida, buscou-se verificar se as informações existentes permitiam inferir a maior ou menor eficiência dos serviços públicos assistenciais prestados pela Administração Pública Direta e Indireta, pelas parcerias com o setor privado, espelho e autônomo formalizadas por contratos de gestão.

O estudo encontrou limitação relativa à não existência, seja por meio das consultas via SIC, seja nas consultas aos Portais da Transparência, de informações comparativas sobre o custo e a efetividade entre os serviços de saúde prestados diretamente pela Administração Pública e aqueles prestados por meio da contratualização entabuladas com os entes da Administração Indireta, privados e do terceiro setor, dado que as informações disponibilizadas referiam-se somente a dados financeiros e de repasse. Isto impossibilitou um estudo mais aprofundado com a finalidade de avaliar se as mudanças estratégicas do papel a ser desempenhado pelo Estado trouxeram avanços na efetivação do direito à saúde. 


\section{Resultados}

No âmbito da saúde pública, a superposição do público com o privado nas várias fases da produção e entrega de políticas públicas assumiu contornos e desenhos jurídicos diferenciados, a depender do padrão relacional que se institui, e produziu 12 formatos jurídicos de pactuações para a prestação de serviços de saúde (Quadro 1).

O mapeamento realizado possibilitou delinear um quadro da seguinte forma: i) pactuação intragovernamental, com autarquias (AUT); fundações estatais de direito público (FEDP), sociedades de economia mista (SEM), empresas públicas (EP) e consórcios públicos (CP); ii) pactuação com o setor espelho, com fundações privadas de apoio (FPA); iii) pactuação com o setor autônomo, com serviços sociais autônomos (SSA); iv) pactuação com o terceiro setor, com organizações sociais (OS) e organizações sociais civis de interesse público (OSCIP); e, v) pactuação com entes privados, com parceria público-privada e entidades filantrópicas ou beneficentes, mediante chamada pública ou convênios.

Vê-se, portanto, que instâncias de governo - entre si e com entidades privadas passam a ser sócias na promoção do desenvolvimento econômico e social, apresentando uma organização mais flexível, ágil, eficiente, efetiva e com a sua ação descentralizada. A contratualização passa a ser um instrumento privilegiado para estabelecer uma maior permeabilidade entre Estado e atores societais, na perspectiva de uma administração voltada para resultados e que ofereça maior autonomia e flexibilidade ao serviço público, com metas e indicadores estipulados e cobrados dos gestores públicos e organizações da sociedade civil mediante novas formas accountability (4).

Em relação ao estado de São Paulo, quando verificou-se os procedimentos hospitalares do SUS por local de internação (Quadro 2), percebeu-se a existência de parcerias com entes públicos e privados delineados no Quadro 1, como autarquias estaduais e municipais; consórcios públicos; fundações públicas estaduais e municipais; fundações privadas; empresas públicas; sociedades anônimas; sociedades empresárias e simples limitadas; cooperativas; organizações religiosas; e organizações privadas, em que pese a forte participação da Administração Pública Direta na prestação dos serviços. 
Quadro 2. Parceria público-privada no Estado de São Paulo para prestação de procedimentos hospitalares, por local de internação, em reais $(2015-2019)$

\begin{tabular}{|c|c|c|c|c|c|}
\hline Natureza Jurídica & 2015 & 2016 & 2017 & 2018 & 2019 \\
\hline 1. Administração Pública & 934.182.917,27 & 1.112.936.099,12 & 1.214.123.375,45 & 1.569.644.828,61 & 1.334.154.776,08 \\
\hline $\begin{array}{l}\text { 102-3 Órgão Público do Poder Executivo Estadual } \\
\text { ou do Distrito Federal }\end{array}$ & $484.401 .708,02$ & $511.864 .498,21$ & $526.266 .090,44$ & $700.336 .390,68$ & $728.276 .043,50$ \\
\hline 103-1 Órgão Público do Poder Executivo Municipal & $274.899 .818,85$ & $115.101 .129,03$ & $110.503 .199,27$ & $158.337 .197,58$ & $157.058 .802,26$ \\
\hline 111-2 Autarquia Estadual do Distrito Federal & $120.622 .669,37$ & 242.751 .840 & $337.118 .703,47$ & $397.330 .104,71$ & $98.917 .268,75$ \\
\hline 112-0 Autarquia Municipal & $22.529 .301,99$ & $23.324 .367,91$ & $24.198 .859,09$ & $27.136 .793,72$ & $32.769 .362,03$ \\
\hline 113-9 Fundação Pública de Direito Público Federal & $84.340,07$ & $363.151,40$ & 0,00 & 0,00 & 0,00 \\
\hline 115-5 Fundação de Direito Público Municipal & $3.823 .291,22$ & $3.939 .045,42$ & $3.391 .213,67$ & $4.712 .958,57$ & $4.956 .133,45$ \\
\hline 120-1 Fundo Público & $353.179,33$ & $14.655,70$ & $446.496,67$ & 9.120 .995 & 0,00 \\
\hline $\begin{array}{l}\text { 121-0 Consórcio Público de Direito Público } \\
\text { (Associação Pública) }\end{array}$ & $8.147 .386,34$ & $8.848 .420,78$ & $186.541 .543,81$ & $250.968 .123,78$ & $9.064 .763,00$ \\
\hline 124-4 Município & $16.013 .720,93$ & $189.067 .642,28$ & $17.657 .269,03$ & $21.702 .264,74$ & $299.252 .400,53$ \\
\hline $\begin{array}{l}\text { 127-9 Fundação Pública de Direito Privado } \\
\text { Municipal }\end{array}$ & $3.307 .501,15$ & $17.661 .348,45$ & $17.945 .494,33$ & 23.943.241,11 & $3.860 .002,56$ \\
\hline 2. Entidades empresariais & 21.582.274,81 & 19.245.213,36 & $544.679,00$ & 23.943.241,11 & $22.416 .860,83$ \\
\hline 201-1 Empresa Pública & 0,00 & 0,00 & $605.731,26$ & $862.038,19$ & $825.316,12$ \\
\hline 204-6 Sociedade Anônima Aberta & $512.976,81$ & $5.426 .678,85$ & $7.147 .757,76$ & 13.505 .583 & $13.943 .432,54$ \\
\hline 205-4 Sociedade Anônima Fechada & $512.976,81$ & $5.426 .678,85$ & $7.147 .757,76$ & $13.505 .583,31$ & $13.943 .432,34$ \\
\hline 214-3 Cooperativa & $80.436,71$ & $993.005,30$ & $2.314 .365,95$ & $4.373 .484,14$ & $5.620 .749,85$ \\
\hline 224-0 Sociedade Simples Limitada & $3.439 .224,59$ & $3.427 .121,04$ & $2.037 .912,21$ & $1.567 .531,74$ & $1.560 .353,03$ \\
\hline 3. Entidades sem fins lucrativos & $1.165 .110 .850,01$ & $1.531 .358 .986,90$ & $1.464 .615 .722,97$ & $1.846 .302 .944,22$ & 2.209.674.729,46 \\
\hline 306-9 Fundação Privada & $638.634 .859,34$ & $494.361 .861,46$ & $422.914 .226,51$ & $576.581 .638,65$ & $916.921 .563,39$ \\
\hline 322-0 Organização Religiosa & $7.151 .354,74$ & $14.081 .771,52$ & $13.749 .194,22$ & $14.699 .307,36$ & $14.305 .074,34$ \\
\hline 399-9 Associação Privada & $1.029 .324 .635,93$ & $1.022 .915 .353,92$ & $1.027 .952 .302,24$ & $1.255 .021 .998,21$ & $1.278 .448 .074,34$ \\
\hline Total & $2.630 .876 .042,09$ & $2.663 .540 .229,38$ & $2.696 .684 .592,75$ & $3.439 .891 .013,94$ & $3.566 .246 .366,37$ \\
\hline
\end{tabular}

Fonte: Ministério da Saúde/Sistema de Informações Hospitalares do SUS (SIH/SUS). Disponível em: http://tabnet.datasus.gov.br/cgi/deftohtm.exe?sih/cnv/qisp.def.

*Dados referentes aos últimos seis meses, sujeitos a atualização.

**A partir de novembro de 2015, estão disponíveis como "Natureza Jurídica" e "Esfera Jurídica". 
Quadro 3. Parceria público-privada no Estado de São Paulo para prestação de procedimentos ambulatoriais, por gestor de serviço, em reais (2015-2019)

\begin{tabular}{|c|c|c|c|c|c|}
\hline Natureza Jurídica & 2015 & 2016 & 2017 & 2018 & 2019 \\
\hline 1. Administração Pública & $2.688 .115 .544,56$ & 2.863.407.079,94 & $2.972 .868 .013,86$ & 3.008.743.139,73 & 2.926.123.997,03 \\
\hline 101-5 Órgão Público do Poder Executivo Federal & - & 4,00 & - & - & - \\
\hline $\begin{array}{l}\text { 102-3 Órgão Público do Poder Executivo Estadual } \\
\text { ou do Distrito Federal }\end{array}$ & $1.016 .792 .964,46$ & $1.015 .580 .504,34$ & $1.056 .151 .065,12$ & $1.048 .069 .586,09$ & $995.283 .827,52$ \\
\hline 103-1 Órgão Público do Poder Executivo Municipal & $1.329 .129 .527,22$ & $364.310 .820,72$ & $355.676 .214,34$ & $367.496 .354,64$ & $387.935 .939,35$ \\
\hline 111-2 Autarquia Estadual do Distrito Federal & $176.634 .736,38$ & 273.461 .986 & $336.590 .986,73$ & $323.880 .839,02$ & $123.420 .824,80$ \\
\hline 112-0 Autarquia Municipal & $22.284 .921,02$ & $21.484 .892,69$ & $22.223 .105,26$ & $21.171 .612,94$ & $26.343 .198,98$ \\
\hline 113-9 Fundação Pública de Direito Público Federal & $784.874,72$ & $1.460 .555,80$ & $123.776,90$ & $167.744,68$ & $104.189,25$ \\
\hline $\begin{array}{l}\text { 114-7 Fundação Pública de Direito Público } \\
\text { Estadual ou do Distrito }\end{array}$ & $31.964 .715,76$ & $30.334 .433,75$ & $30.586 .730,80$ & $31.694 .164,15$ & $33.030 .399,02$ \\
\hline 115-5 Fundação de Direito Público Municipal & $16.042 .377,29$ & $14.488 .066,42$ & $14.954 .762,05$ & $15.170 .217,64$ & $16.249 .690,49$ \\
\hline 120-1 Fundo Público & $7.794 .188,94$ & $110.116,98$ & - & - & - \\
\hline $\begin{array}{l}\text { 121-0 Consórcio Público de Direito Público } \\
\text { (Associação Pública) }\end{array}$ & $13.039 .510,48$ & $13.411 .407,97$ & $12.911 .990,18$ & $12.828 .335,54$ & $14.372 .364,05$ \\
\hline 124-4 Município & $70.297 .641,34$ & $1.116 .098 .517,27$ & $1.130 .030 .028,55$ & $1.173 .725 .790,15$ & $1.323 .342 .027,29$ \\
\hline $\begin{array}{l}\text { 127-9 Fundação Pública de Direito Privado } \\
\text { Municipal }\end{array}$ & $1.409 .618,43$ & $12.172 .895,05$ & $13.115 .945,39$ & $13.991 .319,20$ & $6.040 .536,28$ \\
\hline 2. Entidades empresariais & $582.597 .711,81$ & $572.958 .479,22$ & $602.533 .710,80$ & $610.700 .587,04$ & $663.565 .636,00$ \\
\hline 201-1 Empresa Pública & $354.291,60$ & $380.293,05$ & $1.282 .401,53$ & $1.057 .903,12$ & $1.322 .018,60$ \\
\hline 204-6 Sociedade Anônima Aberta & $8.431,56$ & $39.017,76$ & $16.974,19$ & - & - \\
\hline 205-4 Sociedade Anônima Fechada & $3.214 .785,47$ & $660.734,05$ & $5.634 .489,59$ & $5.956 .799,60$ & $6.451 .139,87$ \\
\hline 206-2 Sociedade Empresária Limitada & $448.892 .754,41$ & $439.195 .565,88$ & $450.700 .303,01$ & $470.009 .110,77$ & $525.571 .587,23$ \\
\hline 213-5 Empresário (Individual) & $1.681 .436,78$ & $1.321 .970,10$ & $1.388 .268,56$ & $1.897 .921,80$ & $2.694 .285,02$ \\
\hline 214-3 Cooperativa & $68.882,90$ & $142.204,93$ & $157.295,47$ & $271.111,11$ & $334.130,66$ \\
\hline 223-2 Sociedade Simples Pura & $12.831 .672,04$ & $13.863 .182,24$ & $13.672 .816,93$ & $16.471 .572,80$ & $20.819 .095,23$ \\
\hline 224-0 Sociedade Simples Limitada & $110.276 .497,95$ & $110.005 .626,49$ & $120.818 .536,49$ & $110.050 .763,58$ & $96.180 .586,85$ \\
\hline $\begin{array}{l}\text { 230-5 Empresa Individual de Responsabilidade } \\
\text { Limitada (de Natureza Empresária) }\end{array}$ & $4.268 .959,10$ & $3.334 .526,82$ & $8.790 .906,75$ & $4.916 .763,32$ & $10.095 .251,08$ \\
\hline
\end{tabular}




\begin{tabular}{|l|l|l|l|l|l|}
\hline Natureza Jurídica & \multicolumn{1}{|c|}{$\mathbf{2 0 1 5}$} & \multicolumn{1}{|c|}{$\mathbf{2 0 1 6}$} & \multicolumn{1}{|c|}{$\mathbf{2 0 1 7}$} & \multicolumn{1}{|c|}{$\mathbf{2 0 1 9}$} \\
\hline 3. Entidades sem fins lucrativos & $\mathbf{1 . 8 8 0 . 0 7 4 . 9 5 0 , 6 5}$ & $\mathbf{1 . 8 2 0 . 9 9 3 . 4 8 4 , 8 3}$ & $\mathbf{1 . 8 9 0 . 8 6 8 . 8 6 6 , 7 4}$ & $\mathbf{1 . 9 8 3 . 0 8 2 . 9 8 4 , 4 4}$ & $\mathbf{2 . 2 3 4 . 5 4 1 . 9 2 4 , 9 6}$ \\
\hline 306-9 Fundação Privada & $605.277 .714,70$ & $505.366 .577,25$ & $462.284 .796,42$ & $509.959 .786,90$ & $723,195,745,44$ \\
\hline 313-1 Entidade Sindical & 651,00 & 688,25 & 133,00 & 56,00 \\
\hline 322-0 Organização Religiosa & $245.347,36$ & $457.248,64$ & $582.955,32$ & $688.685,09$ \\
\hline 399-9 Associação Privada & $1.274 .551 .237,59$ & $1.315 .168 .970,69$ & $1.428 .000 .982,00$ & $1.472 .434 .276,45$ & $1.510 .794 .410,24$ \\
\hline 4. Pessoas físicas & $\mathbf{4 9 6 . 5 2 0 , 2 4}$ & $\mathbf{7 8 5 . 7 7 6 , 5 6}$ & $\mathbf{8 5 4 . 6 3 4 , 3 3}$ & $\mathbf{7 3 5 . 9 3 2 , 2 2}$ & $\mathbf{3 6 1 . 3 7 1 , 3 3}$ \\
\hline 401-4 Empresa Individual Imobiliária & $163.931,91$ & $149.116,95$ & $195.394,20$ & $129.277,28$ \\
\hline Não especificado ou ignorado & $3.633 .930,46$ & - & - & - \\
\hline Total & $\mathbf{1 5 4 . 9 1 8 . 6 5 8 , 0 0}$ & $\mathbf{5 . 2 5 8 . 1 4 4 . 8 2 0 , 5 5}$ & $\mathbf{5 . 4 6 7 . 1 2 5 . 2 2 5 , 8 3}$ & $\mathbf{5 . 6 0 2 . 2 6 2 . 6 4 3 , 4 3}$ & $\mathbf{5 . 8 2 4 . 5 9 2 . 9 2 9 , 3 2}$ \\
\hline
\end{tabular}

Fonte: Ministério da Saúde/Sistema de Informações Hospitalares do SUS (SIH/SUS). Disponível em: http://tabnet.datasus.gov.br/cgi/deftohtm.exe?sih/cnv/qisp.def.

*Dados relativos aos valores de produção apresentados por cada entidade. 
Quando a prestação ambulatorial foi considerada por gestor do serviço (Quadro 3), observou-se uma maior atuação parceirizada em detrimento da participação direta pública. Tal prestação se dá também por entes da Administração Pública Indireta, entidades empresariais, inclusive por empresários individuais e por empresários individuais de responsabilidade limitada, hoje substituída pela sociedade limitada unipessoal, entidades sem fins lucrativos e pessoas físicas, conforme Quadro 3.

A seguir, levantou-se a participação do estado na área da saúde nos instrumentos jurídicos vigentes em 2019, a fim de verificar os repasses financeiros feitos pelo estado de São Paulo para execução dos serviços de saúde via parceirização, conforme Quadro 4.

Quadro 4. Repasses financeiros do Estado de São Paulo para execução de serviços de saúde por entidades públicas e privados, no ano de 2019

\begin{tabular}{|l|c|c|}
\hline \multicolumn{2}{|c|}{ Participação do Estado - Área da Saúde } \\
\hline \multicolumn{1}{|c|}{ Instrumento jurídico } & Forma de participação & Valor da participação \\
\hline Contrato de Gestão & Financeira & 18,96 bilhões \\
\hline Convênio & Financeira & 1,15 bilhões \\
\hline Termo de Fomento & Financeira & 172,29 milhões \\
\hline Termo de Parceria & Financeira & 284,48 bilhões \\
\hline
\end{tabular}

Fonte: adaptado pelo autor. Cadastro de Parceiros do Terceiro Setor (CPATES)/Secretaria da Fazenda e Planejamento de São Paulo. Disponível em: http://www.fazenda.sp.gov.br/CPATES/Sistema/PesqlntrJuri.aspx

Os novos padrões adotados pela Administração Pública devem implementar ferramentas típicas do setor privado, com ênfase numa lógica mais contratual. Porém, após consulta aos instrumentos de transparência disponíveis, deparou-se com um déficit significativo de informações em relação a indicadores aptos a ensejar a construção ou padronização dos dados de performance entre os serviços públicos de saúde prestados pela Administração Direta e aqueles prestados mediante parcerias com a Administração Indireta e o setor privado. Tal lacuna, além de não permitir a fiscalização e cobrança das políticas públicas em saúde, também não permite aferir o maior custo/efetividade entre os serviços de saúde prestados diretamente pela Administração Pública e aqueles prestados pelo privado, em especial pelas Organizações Sociais e Consórcios Públicos.

Os instrumentos de transparência disponíveis estão mais lastreados em dados financeiros e de repasses e menos na chamada accountability de resultados, apta a ensejar uma avaliação comparativa entre os ganhos em eficiência da forma pública de prestação e dos entes privados. Há uma predominância em procedimentos contábeis e financeiros, 
conforme dados obtidos junto ao Portal Financeiro do Gestor da Secretaria Estadual da Saúde, do Portal da Transparência Estadual e do Tabnet DATASUS.

Além disso, a Comissão Parlamentar de Inquérito ( $\mathrm{CPI})$, instaurada na Assembleia Legislativa de São Paulo para investigar irregularidades em serviços prestados em hospitais e unidades de saúde estaduais com parceria com organizações sociais (24), fez críticas ao planejamento e a definição de indicadores de desempenho nos contratos de gestão. Para a Comissão, os contratos de gestão são abertos e imprecisos, o que prejudica a verificação comparativa dos desempenhos entre o público e o privado na prestação dos serviços de saúde e os controles interno, externo e social das demonstrações de resultados dos modelos de prestação de serviços existentes na área da saúde (accountability).

Quanto à correta aplicação dos recursos públicos repassados, a CPI apontou que, em que pese tais modelos tenham proporcionado uma rápida expansão da rede de atendimento, a experiência com as parcerias apresentou lacunas que permitiram graves irregularidades, como desvio de recursos públicos, casos de favorecimento e precarização dos serviços oferecidos aos usuários do SUS. Por sua vez, o Tribunal de Contas do Estado de São Paulo (TCE/SP), em seus apontamentos remetidos aquela Comissão, informou a existência de sérios desvios de finalidade nos serviços de saúde, além de descumprimento de metas estabelecidas, de despesas incompatíveis com o objeto pactuado, e de terceirização e quarteirização de atividade-fim em hospitais, ambulatórios, centros de referência para idosos, centros de reabilitação, serviços de diagnóstico por imagem, centros de armazenamento e distribuição de insumos de saúde e regulação de ofertas de serviços de Saúde.

Não se pretende aqui consagrar uma postura totalitária do Estado por meio da Administração Pública. Deve existir uma autoadministração compreendida pela partilha de competências administrativas entre o Estado; as entidades administrativas autônoma territoriais (estados e municípios), associativas e institucionais; e a iniciativa privada na produção de bens e serviços a determinada parcela da população que dependa de sua atuação para fazer efetivar os seus direitos sociais (4). Porém, como bem apontado pela $\mathrm{CPI}$, há a necessidade de se garantir que tais serviços parceirizados sejam tratados com a lisura e transparência que o caso requer, pois são custeados com recursos públicos e destinados a uma área sensível como a saúde pública, onde a demanda por serviços é crescente e o financiamento cada vez mais escasso. 


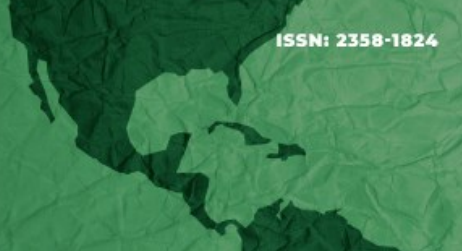

\section{Discussão}

Num primeiro momento, verificou-se que a discussão em torno das contratualizações, especialmente no âmbito das políticas públicas de saúde, tem como premissa central a transferência de recursos públicos, o que restringe a análise de seus fatores condicionantes somente às questões de natureza econômica. Não há uma análise de como são formas de intermediação de interesses que privilegiem aspectos mais direcionados à eficiência da prestação do serviço público em si, conforme se depreende das pesquisas nos sistemas de transparência e accountability governamentais.

Nas informações sobre procedimentos hospitalares por local de internação e ambulatoriais por gestor do SUS disponibilizadas por natureza jurídica do prestador (Quadros 2 e 3), observou-se que os dados oferecidos referem-se a aspectos orçamentários e financeiros relacionados a investimento e custeio, sem qualquer dado comparativo que demonstre padrões de performance; alcance das metas e resultados colimados; ou a maior ou menor eficiência da prestação de serviços de saúde descentralizado, em detrimento da prestação direta pela Administração Pública. Doutro bordo, podemos observar que o modo, a provisão e a gestão de serviços pela iniciativa privada - complementares ao papel do Estado - ainda ocorrem sob nítida dependência da esfera governamental, com expressivas e permanentes transferências do fundo público para seu financiamento, expansão e consolidação (25).

Em relação aos hospitais administrados pelas Organizações Sociais (em especial os hospitais gerais), por exemplo, tem sido defendido que apresentam, de forma geral, melhor desempenho e produtividade do que os hospitais próprios administrados pela Secretaria Estadual de Saúde de São Paulo, e creditando tal resultado à maior autonomia de gestão; à melhor estruturação dos processos de trabalho, como o de aquisição de bens e insumos; e à movimentação de pessoal (como a admissão, valorização, substituição e demissão de recursos humanos), associados, ainda à contratualização, por meio da definição de metas a serem alcançadas (10). Mas, em que pese a descentralização dos serviços públicos de saúde, todos os entes descentralizados contam com a participação do ente público no custeio e investimento para sua manutenção, sendo possível verificar que predomina a prestação de serviços de saúde por meio de contratos de gestão com o terceiro setor.

As consultas empreendidas nos Portais de Transparência possibilitaram a construção de quadros comparativos somente com dados financeiros, não tendo sido encontrados 
quaisquer indicadores que possibilitassem a elaboração de uma análise comparativa quanto à maior eficiência da prestação de serviços por tais entidades em relação à prestação por intermédio dos próprios Administração Pública Direta. Também não encontramos qualquer informação que demonstre ausência de objetivos, limitação da autonomia, improvisação gerencial, desperdício de recursos públicos ou mesmo de baixa responsabilidade em relação a resultados na Administração Pública Direta, fatores sempre utilizados para justificar a celebração de contratos de gestão com entes privados e do terceiro setor. Embora a análise do desempenho organizacional seja essencial para orientar e propor alterações que resultem em uma melhor eficiência, fato é que não existe um consenso sobre como operacionalizála, pois, mesmo que a literatura disponibilize inúmeras medidas de desempenho, nenhuma, isoladamente, seria tida como capaz de abranger todos os aspectos relevantes do desempenho organizacional.

A ausência de informações relativas ao desempenho organizacional das parcerias com entidades privadas alimenta a tese de que a contratação com entidades privadas e do terceiro setor se dão para possibilitar a fuga dos preceitos constitucionais da licitação e do concurso público que balizam a Administração Pública. Isso reforça a crítica quanto a uma aplicação indiscriminada do Direito Privado como forma de escapar dos controles de Direito Administrativo, e quanto à restrição da proteção social garantida constitucionalmente por meio do aumento dos processos de privatização que têm implicado na mercantilização das condições de bem-estar dos indivíduos.

Conforme mencionado pela CPI das OSs, existem imperfeições que precisam ser pensadas - tanto no aspecto legal quando no próprio instrumento de contratualização -, de forma a garantir uma melhor definição do objeto, delimitação do escopo e estimativa de valor, de modo a permitir que se verifique a real pertinência e justificativa da contratação, conferindo maior transparência. Assim, fora a obtenção de dados financeiros, não foi possível encontrar qualquer avaliação relativa ao custo e efetividade entre prestação direta e parceirização que demonstre que os hospitais e ambulatórios administrados por exemplo pelas OSs apresentam, de forma geral, melhor produtividade do que os hospitais geridos pela Administração Pública Direta. Corrobora esse entendimento a progressiva perda da capacidade gerencial do Estado brasileiro em decorrência da privatização e a expansão do setor privado de saúde, respaldada pelo próprio Estado e seus níveis de governo (26), e o 
financiamento inadequado do setor público, que está abaixo do previsto pela Constituição Federal e de países que possuem sistema universal de saúde (15).

Frise-se que os novos modelos de prestação de serviços de saúde, oriundos das pactuações mencionadas no presente trabalho, têm como pressuposto, por expressa determinação legal, a realização avaliações periódicas. A fragmentação e delegação de serviços a vários entes e entidades, por meio de diversas formas de contratação e estabelecimento de metas e resultados, dificulta o controle, tanto social, quanto governamental, reforçando o papel da promoção e estímulo à transparência como uma das questões-chave da Administração Pública contemporânea. O cenário de parcerias públicoprivada nos deixa, muitas vezes, uma sensação de que a divisão de atividades se dá sem controles e sem enquadramentos jurídicos adequados. O déficit de sistematização das diversas estruturas e atividades administrativas públicas ou privadas (4) - necessária para o estabelecimento de um controle seja pelo Estado seja pelo cidadão - corrobora outro achado da própria CPI: a necessidade de um novo marco regulatório.

\section{Conclusão}

No nível da análise teórica, a transformação do papel desempenhado pelos Estados, em especial dos anos 90, intensificou as práticas reformistas nos segmentos governamentais em função das disfunções burocráticas do Estado Social contemporâneo. Percebeu-se a necessidade de se buscar novos paradigmas para a prestação dos serviços de saúde.

Assim, a transferência de responsabilidades dos serviços tidos como não essenciais do Estado, como a saúde, culminou com a criação de novos modelos de prestação de serviços de saúde oriundos das pactuações com a iniciativa privada, o terceiro setor, o setor espelho e o setor autônomo. No entanto, não foi encontrado, seja na literatura, seja por intermédio das informações disponibilizadas nos Portais da Transparência, comprovação científica ou mesmo empírica que assegure a eficiência dessas novas formas de coalizões, alianças, parcerias e redes que envolvam a sociedade civil, o mercado e os diferentes níveis de governo - especialmente na forma de contratos de gestão - como opção de oferta de políticas públicas de corte social.

No estado de São Paulo, a falta de ferramentas e instrumentos de accountability governamental acaba por ocasionar pouca transparência nos instrumentos de avaliação de 


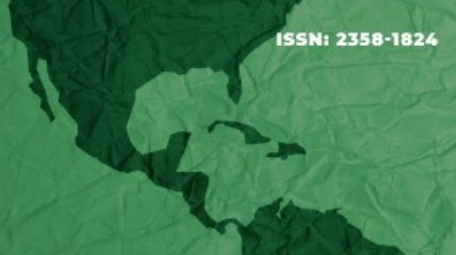

metas e resultados colimados nas contratualizações entabuladas, em especial nos contratos de gestão. Também dificulta o controle social dos referidos dados e das disfunções práticas apontadas na prestação de serviços públicos de saúde pelas entidades da iniciativa privada. Nesse sentido, a melhoria da governança em rede é também primordial, para que a sociedade decida, mediante instrumentos de participação social, os rumos que as ações estatais de saúde pública devem tomar no Brasil.

\section{Referências}

1. Brasil. Emenda Constitucional $n^{\circ} 19$, de 04 de junho de 1998. Modifica o regime e dispõe sobre princípios e normas da Administração Pública, servidores e agentes políticos, controle de despesas e finanças públicas e custeio de atividades a cargo do Distrito Federal, e dá outras providências. Diário Oficial da União: seção 1, p. 1, Brasília, DF, ano CXXXV, n. 106-E, p. 1-3, 05 jun.1998.

2. Bresser Pereira LC. A reforma do estado dos anos 90: lógica e mecanismos de controle. Lua Nova: Revista de Cultura e Política [Internet]. 1998 [citado em 04 out. 2021]; 45:49-95. Disponível em: https://doi.org/10.1590/S0102-64451998000300004. doi https://doi.org/10.1590/S0102-64451998000300004.

3. Oliveira GJ. Contrato de Gestão. São Paulo: Editora Revista dos Tribunais; 2008.

4. Freitas DB. A fragmentação administrativa do Estado - fatores determinantes, limitações e problemas jurídico-políticos. Belo Horizonte: Ed. Fórum; 2011.

5. Batista Junior OA. Transações administrativas. São Paulo: Quartier Latin; 2007.

6. Moncada LSC. A relação jurídica administrativa: para um novo paradigma de compreensão da atividade, da organização e do contencioso administrativo. Coimbra: Coimbra Editora; 2009.

7. Tácito C. Direito administrativo participativo. Revista de Direito Administrativo [Internet]. 2005 (citado em 09 ago. 2019]; 242:133-138. Disponível em: http://bibliotecadigital.fgv.br/ojs/index.php/rda/article/view/42974/44592. doi http://dx.doi.org/10.12660/rda.v242.2005.42974

8. Sundfeld CA. O Direito Administrativo entre os clips e os negócios. In: Aragão AL, Santos A, Marques Neto FA, editores. Direito administrativo e seus novos paradigmas. Belo Horizonte: Fórum; 2008. p. 87-93.

9. Tácito C. Transformações de Direito Administrativo. Revista de Direito Administrativo [Internet]. 1988 [citado em 09 ago. 2019]; 214:27-34. Disponível em: http://bibliotecadigital.fgv.br/ojs/index.php/rda/article/view/47264. doi http://dx.doi.org/10.12660/rda.v214.1998.47264. 
10. Rodrigues RC et al. Rede hospitalar estadual: resultados da administração direta e das organizações sociais. Revista de Administração em Saúde [Internet]. 2014 [citado em 04 out. 2021); 16(65):111-122. Disponível em:

http://portal.saude.sp.gov.br/resources/ses/perfil/gestor/destaques/gais-informa/outraspublicacoes-e-analises/ras_2015001_rede_hospitalar_estadual_oss_e_ad.pdf. doi http://10.5327/Z1519-1672201400650002.

11. Brasil. Lei $n^{\circ} 12.527$, de 18 de novembro de 2011. Regula o acesso a informações previsto no inciso XXXIII do art. $5^{\circ}$, no inciso II do $\S 3^{\circ}$ do art. 37 e no $\S 2^{\circ}$ do art. 216 da Constituição Federal; altera a Lei $n^{\circ}$ 8.112, de 11 de dezembro de 1990; revoga a Lei $n^{\circ}$ 11.111, de 5 de maio de 2005, e dispositivos da Lei $n^{\circ} 8.159$, de 8 de janeiro de 1991; e dá outras providências. Diário Oficial da União, Brasília, DF, 18 nov.2011, p. 1, Seção 1, Edição Extra, p.1-4, 13 out.2021.

12. Aith FMA. Direito à saúde e democracia sanitária. São Paulo: Quartier Latin; 2017.

13. Opas. Organização Pan-Americana de Saúde. Plano Estratégico da Organização PanAmericana da Saúde 2014-2019. 29 set. 2014 [citado em 24 jun. 2019]. Washington: Opas, 2013. 141p. Disponível em: https://www.paho.org/hq/dmdocuments/2017/paho-strategicplan-por-2014-2019.pdf.

14. Arretche M. Democracia e Redução da Desigualdade Econômica no Brasil: a inclusão dos outsiders. Revista Brasileira de Ciências Sociais [Internet]. 2018 [citado em 18 jun. 2019]; 33(96):2-23. Disponível em: http://www.scielo.br/pdf/rbcsoc/v33n96/0102-6909rbcsoc-3396132018.pdf. doi http://dx.doi.org/10.17666/339613/2018.

15. Giovanella $L$ et al. Sistema universal de saúde e cobertura universal: desvendando pressupostos e estratégias. Ciências da Saúde Coletiva [Internet]. 2018 [citado em 04 out. 2021]; 23(6):1763-1776. Disponível em: http://www.scielo.br/scielo.php?script=sci_arttext\&pid=S141381232018000601763\&Ing=en\&nrm=iso. doi http://dx.doi.org/10.1590/141381232018236.05562018

16. Maggio MP, Dallari SG. A efetivação jurídico-política do Direito à Saúde no Supremo Tribunal Federal: a referência paradigmática da SL 47-AGR/PE. Revista de Direito Sanitário [Internet]. 2017 [citado em 10 jun. 2018]; 17(3): 58-76. Disponível em: http://www.revistas.usp.br/rdisan/article/view/127776/124773. doi https://doi.org/10.11606/issn.2316-9044.v17i3p58-76

17. Brasil. Lei $n^{\circ} 8.080$, de 19 de setembro de 1990. Dispõe sobre as condições para a promoção, proteção e recuperação da saúde, a organização e o funcionamento dos serviços correspondentes e dá outras providências. Diário Oficial da União: seção 1, Brasília, DF, Ano CXXVIII, n. 182, p. 18055-18059, 19 ago.2021.

18. Marques Neto FA. Público e Privado no Setor da Saúde. Revista de Direito Público da Economia - RDPE. Belo Horizonte, 2005; (9):105-151. 

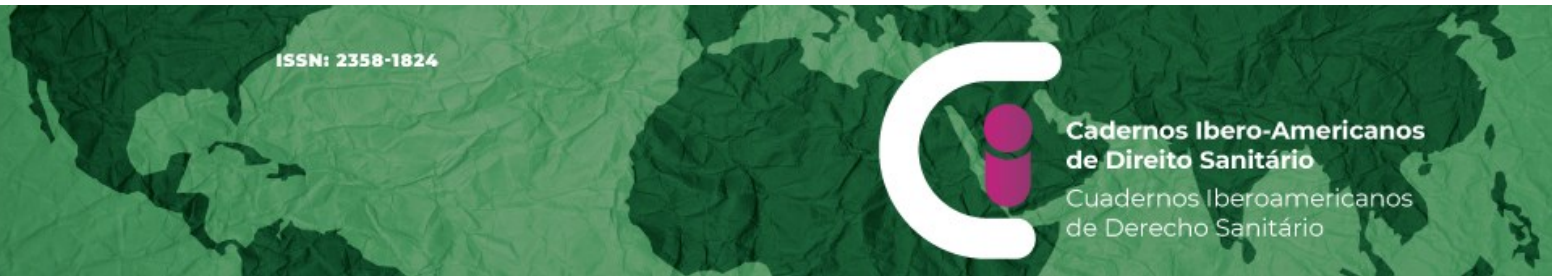

19. Carvalho Filho JS. Estado Mínimo x Estado Máximo: o dilema. Revista Eletrônica de Direito Administrativo (RERE) [Internet]. 2008 [citado em 07 jun. 2018]; (12):1-18. Disponível em: http://www.direitodoestado.com.br/codrevista.asp?cod=250

20. Torchia M, Calabró A, Morner M. Public-private partnerships in health care sector: a systematic review of the literature. Public Management Review 2015; 17:236-61.

21. Moreira Neto DF. Natureza jurídica dos serviços sociais autônomos. Revista de Direito Administrativo [Internet], 1997 [citado em 27 jun. 2019]; 207:79-94. Disponível em: http://bibliotecadigital.fgv.br/ojs/index.php/rda/article/view/46938. doi http://dx.doi.org/10.12660/rda.v207.1997.46938

22. Aith FMA. Direito à saúde e democracia sanitária: experiências brasileiras. Revista de Direito Sanitário [Internet]. 2015 [24 jun. 2019]; 15(3):85-90. Disponível em: http://www.revistas.usp.br/rdisan/article/view/97328/96340. jun.2019. doi https://doi.org/10.11606/issn.2316-9044.v15i3p85-90

23. Aith F, Bujdoso Y, Nascimento PR, Dallari SF. Os princípios da universalidade e integralidade do SUS sob a perspectiva da política de doenças raras e da incorporação tecnológica. Revista de Direito Sanitário [Internet]. 2014 [citado em 04 mai. 2018]; 15(1):1039. Disponível em: http://www.revistas.usp.br/rdisan/article/view/82804/85759. doi https://doi.org/10.11606/issn.2316-9044.v15i1p10-39

24. São Paulo. Assembléia Legislativa. CPI - Organizações Sociais - OSs. Comissão Parlamentar de Inquérito criada pelo Ato $n^{\circ} 02$, de 2018, do Presidente da Assembleia, mediante Requerimento $n^{\circ} 2928$, de 2017. Diário Oficial do Estado de São Paulo: São Paulo, Suplemento, SP, volume 128, n. 175, p.1-2, 25 set.2018. Disponível em: https://www.al.sp.gov.br/repositorio/arquivoWeb/com/com5772.pdf

25. Morais HMM, Albuquerque MSV, Oliveira RS, Cazuzu AKI, Silva NAF. Organizações Sociais da Saúde: uma expressão fenomênica da privatização da saúde no Brasil. Caderno Saúde Pública [Internet]. 2018 [citado em 28 jun. 2019]; 34(1):1-13. Disponível em: http://www.scielo.br/scielo.php?script=sci_abstract\&pid=S0102311 X2018000105017\&lng=en\&nrm=iso\&t|ng=pt. doi http://dx.doi.org/10.1590/0102$311 \times 00194916$

26. Travagin LB. O avanço do capital na saúde: um olhar crítico às Organizações Sociais de Saúde. Saúde debate [Internet]. 2017 [04 out. 2021]; 41(115):995-1006. Disponível em: http://www.scielo.br/scielo.php?script=sci_arttext\&pid=S010311042017000400995\&lng=en\&nrm=iso. doi http://dx.doi.org/10.1590/0103-110420171150

\section{Colaboradores}

Biancardi Barboza PI contribuiu para a concepção e desenho do artigo, análise e interpretação de dados e redação do artigo. Vasconcellos MP contribuiu para a concepção 


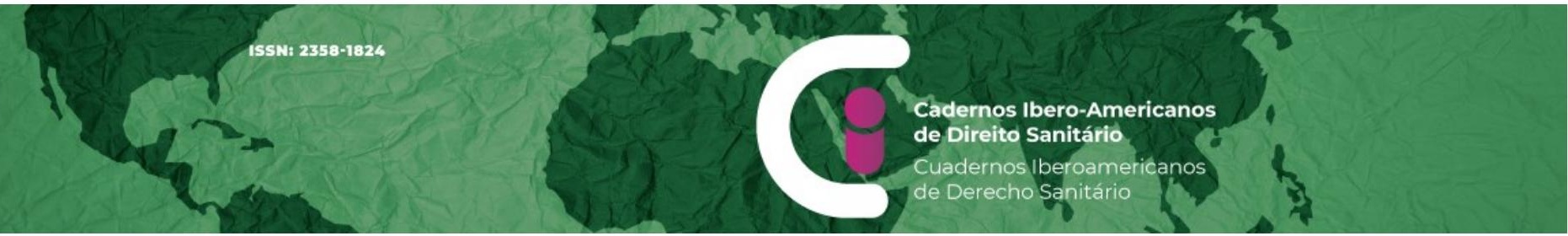

e desenho do artigo, revisão crítica de seu conteúdo e aprovação da versão final do artigo. Aith FMA contribuiu para a revisão crítica do conteúdo e aprovação da versão final do artigo.

Como citar este artigo

Biancardi Barboza PI, Vasconcellos MP, Aith FMA. Transparência nas relações público-privadas para prestação de serviços de saúde no estado de São Paulo. Cadernos Ibero-Americanos de Direito Sanitário. 2021 out./dez.;10(4):125152.

https://doi.org/10.17566/ciads.v10i4.810 